example, the statement on p. 87 that "individuals heterozygous for the gene determining $\mathrm{Hb} S$ invariably possess both $H b A$ and $H b C^{\prime \prime}$. This is corrected later in the same paragraph. However, I have detected no serious mistake. It can be read with great benefit by students of other branches of genetics, and of medicine. Some knowledge of both genetics and pathology is assumed. The alternative would have been to double the volume and price of the book. Helen Lang Brown, who helped in editing, and was almost surely responsible for the very full bibliography with 526 references, deserves special thanks.

J. B. S. HALDANE

\section{TECHNICAL APPLICATIONS OF FRESHWATER BIOLOGY}

Handbuch der Frischwasser- und Abwasser-Biologie. Von Prof. Hans Liebmann. Band 2. Lieferung 1: Pp. xi+1-160. Lieferung 2: Pp. 161-320. Lieferung 3: Pp. 321-480. Lieferung 4: Pp. 481-640. Lieferung 5: Pp. 641-800. Lieferung 6: Pp. 801-960. Lieferung 7: Pp. 961-1149. (München: R. Oldenbourg, 1960.) 20 D.M. each number.

$T$

HIS volume is the second of a pair. The first, published in 1951 , dealt with freshwater biological methods and the most important chemical techniques which are needed to supplement them. It contained also an exhaustive treatment of the indicator organisms which can be used in the study of pollution, and a new exposition of the Kolkwitz and Marsson Saprobiensystem, which is widely used in Europe for assessing organic pollution.

The two volumes are intended to be used together, and the second contains many references to the first. In both, the emphasis is on the 'application' of biological knowledge to water technology, and although much basic freshwater biology is included it is clear that the author intends this only as a background. This approach to a subject which is often regarded as primarily academic should commend itself to readers in many disciplines concerned with the uses of water in their widest sense.

The second volume begins with a discussion of the various processes which result in natural selfpurification of organically polluted waters, and this leads to a brief survey of the biology of waters in general, including artificial lakes and reservoirs. It then considers drinking water, with special reference to its origin, since the organisms which occur, or develop, in it vary according to whether it comes from underground or surface sources. Here also are described the various filtration and other methods which are normally employed, and the biological problems which may arise in their use, as well as the difficulties caused by water blooms and their control. A similar, shorter, chapter deals with swimming pools and spas.

A further section covers freshwater fisheries of all kinds, from natural rivers and streams to fish farms, and here again the emphasis is on practical management.

The author then discusses the methods of sewage purification, with particular reference to the biological processes involved. This section is a mine of information on the various processes in use on the Continent, including some, such as fish ponds, sewage ponds and irrigation, which are not used in Britain, but which might well be considered for introduction.
Many readers of biology could learn much about civil engineering from these chapters, as could engineers about how their steel and concrete structures enable micro-organisms to purify effluents. Of particular interest are the accounts of the use of sewage in Munich for rearing carp, and of the biology of trickling filters and activated sludge.

The final section, written in collaboration with Dr. H. A. Stammer, gathers together the scattered literature on the toxicity of inorganic and organic chemicals to freshwater organisms, and the effects of suspended solids and high temperature on fish. It will be most useful for reference.

The book is well illustrated with photographs, and contains diagrams from many original papers. It ends with a hundred closely printed pages of references and a good index. It is, in short, an excellent book to have on one's shelf, or in the nearest library, and Dr. Liebmann is to be congratulated on having performed such a Herculean task.

I have, however, some criticisms. First, 140 D.M. is a very high price for any book, and for this one it seems unnecessarily high. Many points are discussed several times, and liberal application of a blue pencil could have made the book much shorter with no loss of content. Moreover, many figures are reproduced two or three times. There is also a very large number of misprints, only some of which are corrected in three pages of errata. Many of these involve the names of invertebrates, and Dr. Liebmann would have been well advised to submit the proofs to a zoologist. This would also have saved him from calling Suberites a freshwater sponge, mislabelling at least three of his photographs and making several other unnecessary mistakes. More careful editing could have removed these blemishes and lowered the price.

H. B. N. HYNES

\section{PROTON RESONANCE}

\section{Applications of Nuclear Magnetic Resonance Spec-} troscopy in Organic Chemistry

By L. M. Jackman. (International Series of Monographs on Organic Chemistry, Vol. 5.) Pp. xii +134. (London and New York: Pergamon Press, 1959.) 35s. net.

WROM birth to maturity, the application of - nuclear magnetic resonance to problems in organic chemistry spans a period of only five years. Dr. Jackman's book is therefore timely, for which both author and publisher are to be congratulated.

The questions that nuclear magnetic resonance is asked to solve in organic chemistry are: (1) What types and number of protons can be distinguished by their chemical shift? (2) What information about the environment can be obtained when the spin-coupling components are resolved? Both topics are treated in the book although, appropriately (I) is dealt with more thoroughly. While many important spectra are described and analysed, the theoretical content is strongly qualitative, and it is possible to doubt if this severely practical outlook really conveys the elements of the subject to the uninitiated. This is perhaps not the purpose of the book, but it fails to meet the condition that the full deployment of nuclear magnetic resonance in problems of structure involves a better appreciation of its principles than, for example, ultra-violet or infra-red spectroscopy. 